\title{
Article \\ The Impact of Pain on Functionality, Postural Control and Fall Risk in Woman Aged 45 to 64 Years Old
}

\author{
Priscilla Beaupré ${ }^{1}$, Rubens A. da Silva ${ }^{1,2,3,4,5}$ and Tommy Chevrette ${ }^{1,3,6, *}$ \\ 1 Masters of Biomedical Science Program, Université du Québec à Chicoutimi (UQAC), \\ Saguenay, QC G7H 2B1, Canada; priscilla.beaupre1@uqac.ca (P.B.); rubens_dasilva@uqac.ca (R.A.d.S.) \\ 2 Physical Therapy McGill Program in Extension, Université du Québec à Chicoutimi (UQAC), \\ Saguenay, QC G7H 2B1, Canada \\ 3 Centre Intersectoriel en Santé Durable, Département des Sciences de la Santé, Université du Québec à \\ Chicoutimi (UQAC), Saguenay, QC G7H 2B1, Canada \\ 4 Centre Intégré de Santé et Services Sociaux du Saguenay-Lac-Saint-Jean (CIUSSS SLSJ), \\ Specialized Geriatrics Services-La Baie Hospital, Saguenay, QC G7H 7K9, Canada \\ 5 BioNR Research Lab, Département des Sciences de la santé, Université du Québec à Chicoutimi (UQAC), \\ Chicoutimi, QC G7H 2B1, Canada \\ 6 Département des Sciences de la santé, Clinique Universitaire de Kinésiologie, Université du Québec à \\ Chicoutimi (UQAC), Chicoutimi, QC G7H 2B1, Canada \\ * Correspondence: tommy_chevrette@uqac.ca; Tel.: +1-418-545-5011 (ext. 4452)
}

check for updates

Citation: Beaupré, P.; da Silva, R.A.; Chevrette, T. The Impact of Pain on Functionality, Postural Control and Fall Risk in Woman Aged 45 to 64 Years Old. Geriatrics 2022, 7, 10 . https://doi.org/10.3390/ geriatrics7010010

Academic Editor: Ralf Lobmann

Received: 15 December 2021 Accepted: 30 December 2021 Published: 1 January 2022

Publisher's Note: MDPI stays neutral with regard to jurisdictional claims in published maps and institutional affiliations.

Copyright: (C) 2022 by the authors. Licensee MDPI, Basel, Switzerland. This article is an open access article distributed under the terms and conditions of the Creative Commons Attribution (CC BY) license (https:// creativecommons.org/licenses/by/ $4.0 /)$.

\begin{abstract}
Background: Ageing in women is associated with chronic degenerative pain leading to a functional decrease and therefore increase fall risk. It is therefore essential to detect early functional decreases in the presence of pain related to osteoarthritis. Objective: This cross-sectional study aimed to assess the impact of pain on functionality, postural control and fall risk in women aged between 45 to 64 years old. Methods: Twenty-one (21) women aged 45 to 64 were evaluated by clinical and functional measures such as a pain questionnaire (Lequesne Index), functional tests (Stair Step Test, 5 times sit-to-stand, 6MWD, Timed-up and Go) and postural performance (under force platform). Women were classified into 2 groups from the Lequesne Pain Index (PI): low pain (score $\leq 9$ ) and strong pain (score $\geq 10$ ) for subsequent comparisons on functionality (physical and postural control performance). Results: A significant impact was observed between the pain index (strong PI) and 3 of the 4 functional tests carried out including Stair Step Test $(p=0.001 ; g=1.44)$, walking distance $(p=0.003 ; g=1.31)$ and Timed-up and Go $(p=0.04 ; g=-0.93)$. The group with a strong PI score reported further poor postural control under force platform compared to the weak pain group. Conclusion: Pain and severity based on the PI index negatively modulate physical and postural control performance in women aged 45 to 64 years old.
\end{abstract}

Keywords: pain; woman; hip; osteoarthritis; aging

\section{Introduction}

Population ageing is a global phenomenon. According to the United Nations, in 2050, $16 \%$ of the worldwide population will be over 65 years old, up from $9 \%$ in 2019 [1]. Ageing is associated with an increase in age-related health problems such as osteoarthritis (OA) [2]. This problem is defined as a disease characterized by the degeneration of cartilage and its underlying bone within a joint, as well as bony overgrowth. The joints most affected by OA are the weight-bearing joints of the lower limbs [3] followed by hips joints [4] in $25 \%$ of people who develop symptomatic hip OA in their lifetime [5]. Hip OA associated with pain has a significant impact on quality of life as well as an increased fall risk [6].

Joint tissue breakdown eventually leads to pain and joint stiffness [7]. The impact of hip OA leads to a heavy burden of disease [8]. Several studies have evaluated disability and function in patients with hip OA, such as lower extremity muscle strength [9-11], aerobic 
capacity [12,13] or postural control [14]. All results lead to a decrease in functional capacity on the individual who presents hip OA when compared to control subjects [8-14].

The impaired physical function caused by these symptoms increases fall risk in people with OA. Several studies have shown a strong association between OA and falls [15], especially among women [16,17]. Smith et al. [15] have demonstrated that people who are newly diagnosed with hip OA have a 50\% higher risk of experiencing a fall and an $85 \%$ higher risk of experiencing a fracture than people of similar age and characteristics, without hip OA. The most common causes of the increased fall risk in people with hip OA are decreased strength and proprioception in the hip joint, leading to greater instability and reduced ability to compensate postural control when made unstable, and curtailing of physical activity [18-21].

Age is a major factor contributing to the appearance and progression of hip OA [22,23]; it is, however, not the only risk factor. Indeed, female gender [23-26] and obesity [27,28] are other factors that can contribute to early hip OA. Although it is mostly older people who suffer from hip OA [23], hip complaints can appear at an earlier age [5]. To investigate the impact of hip pain, we constructed a battery of 12 functional tests and postural control measures under force platform in the same experimental design for aging women. The purpose of this study was to assess the physical and functional abilities of women aged 45-64 years old with different levels of hip joint pain.

\section{Materials and Methods}

\subsection{Study Design}

A cross-sectional descriptive study was performed between October 2018 and June 2019 at the Université du Québec à Chicoutimi (Quebec, QC, Canada) in the Clinique universitaire de kinésiologie and BioNR Laboratory. We used the Quality Assessment Tool for observational cohort and cross-sectional studies [29] to provide quality and consistency.

\subsection{Participants}

A total of 21 women participated voluntarily in this study by convenience. The sample was recruited using a newspaper ad in the Féderation de l'âge d'Or du Québec, and UQAC social networks and through a kiosk at the Salon de la Femme in Saguenay and selected by one author (PB). Women who fulfilled the inclusion criteria were informed about the study and invited to participate. The inclusion criteria were: (1) being a woman; (2) of caucasian origin and (3) aged between 45 and 64 years old (inclusive). Participants were excluded if they: (1) suffered from a cardiovascular, pulmonary or musculoskeletal disorder that could interfere with the safe performance of physical evaluation, (2) hip arthroplasty or (3) had a self-reported diagnosis of knee osteoarthritis.

Before testing, all women were classified into two groups according to the Lequesne [30] index (PI), which is a questionnaire validated for evaluating the severity index of hip osteoarthritis, with a total of 10 points (see Supplementary Materials, Table S1: Index of Severity for Osteoarthritis of the Hip by Lequesne et al.). A high score refers to significant impairment, while a lower score refers to modest impairment. The groups were then classified in (1) Low PI (score varying of 0 to $9=$ less severe pain) and (2) Strong PI (score $\geq 10$ = strong pain).

\subsection{Data Collection}

One two-hour laboratory session was required for all participants. Sociodemographic and anthropometric data were first collected. Then, five tests were conducted: (1) Five Times Sit-to-Stand Test [31]; (2) the Stair Step Test [32]; (3) the Six-Minute Walk Distance [33]; (4) the Timed-up and Go [34] and (5) postural control with a force platform [35]. All tests and measures were performed according to standard protocols. One author (PB) conducted the assessment of the participants with the help of a trained research assistant. 


\subsubsection{Anthropometric Variables}

Body Mass Index

The body mass index (BMI) was calculated to assess body fat in the clinical setting. This measurement provides a more accurate measure of total fat mass than body weight assessment alone [36]. The calculation was performed according to the National Institute of Health protocol [37] by dividing weight in kilograms by height in square meters $\left(\mathrm{kg} / \mathrm{m}^{2}\right)$.

\section{Waist Circumference}

Waist circumference measurement is another accurate method of assessing the level of health risk associated with obesity or overweight [38]. Waist circumference measurement was taken according to the recommendations of the National Institutes of Health [37].

\subsubsection{Physical and Functional Capacity}

Five Times Sit-to-Stand Test

The five Times Sit-to Stand Test (FTSST) is reliable for a functional evaluation of lower limb strength. The test was performed according to the standardization proposed by Whitney and Wrisley [31]. It requires the participant to stand up and sit down from a chair with arms crossed over the chest five times, as quickly as possible. The score was the time required to complete five sit-to-stand routines. Two trials are permitted with two minutes of rest between trials. We kept the best time of the two trials.

\section{Stair Step Test}

The Stair Step Test measures the participant's ability to alternatively lift each foot and touch the top of a single stair for $20 \mathrm{~s}$. The score was the number of touches executed during the test. Two trials are permitted with a two-minute rest between trials. We kept the best score of the two trials.

\section{Six-Minute Walk Distance}

The Six-Minute Walk Distance Test (6MWD) was used to assess functional exercise capacity. The participant is encouraged to walk the furthest possible distance in six minutes. The reference values used were those recommended by Enright and Sherill [33].

\section{Timed-Up and Go}

The Timed-up and Go (TUG) was used to measure basic mobility and to assess fall risk. The test was performed according to the standardization proposed by Shumway-Cook and Brauer [34]. The participant was asked to walk a three-meter distance, turn around and return to sit back on a chair. Two trials were planned for the test. The best time was kept for analysis.

\section{Postural Control Test on the Force Platform}

The postural control test for all participants was performed using a force platform (BIOMEC 400, EMG System do Brasil, Ltda, Sao Jose dos Campos, SP, Brazil) during two experimental conditions (Figure 1: (1) bipodal and (2) semi-tandem; both with eyes open and closed. Each condition was performed by two trials of $30 \mathrm{~s}$, with a 1-min rest period between each trial and 2 min between each condition [39]. The mean across 2 trials was retained for subsequent analysis. Overall, all participants were asked to take the requested position standing upright on the platform barefoot, arms at their sides, and with eyes open. They were asked to fix an eye-level target on a wall $2 \mathrm{~m}$ away. As a safety measure, a belt was fastened around their waist and a collaborator stood near the participants during the tests to prevent falls. 
(a)

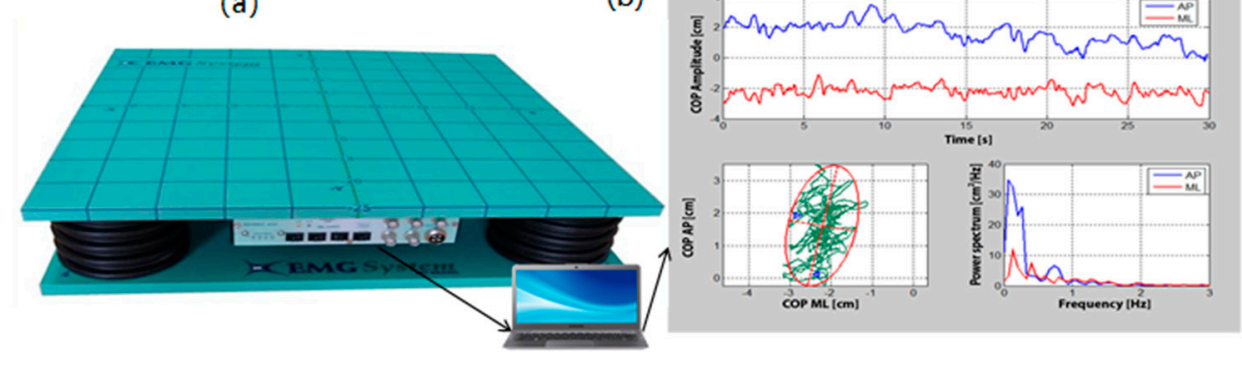

(c)

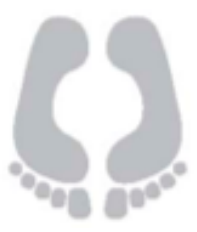

(d)

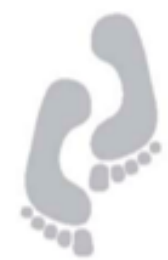

Figure 1. Force plateform and COP measurement. Instrument for measuring with a force platform (BIOMEC400, EMG System do Brasil, Ltda.) (a); and postural control measurements based Pressure Center parameter: COP (elliptical area of the COP, frequency and velocity in the anteroposterior and mediolateral directions (b). Postural control tasks with a standardized protocol in bipodal (c) and semi-tandem (d) postures using leg preference in front.

\section{COP Data Processing}

The COP-based postural parameters were computed with the use of a validated BIOMEC 400 force platform containing 4 strain gauges arrayed in a rectangle. The sensitivity of each sensor is certified to be $0.0015 \%$ for a maximum load of $1000 \mathrm{~N}$ and the variation of $9.999 \mathrm{~N}$ of the force applied to one strain gauge corresponds to a $120-\mathrm{mV}$ variation of the output. The output range runs from 0 to $5 \mathrm{~V}$. Reaction force signals were sampled at $100 \mathrm{~Hz}$ and filtered with a 35-Hz low-pass second-order Butterworth filter and converted into COP data using EMG system do Brasil software which was compiled with MATLAB routines (The Mathworks, Natick, MA, USA). Stabilographic analysis of COP data led to determine the following postural parameters during a $30-$ s trial: $95 \%$ confidence ellipse area of COP (named A-COP: the total area covered in the sagittal and frontal planes using an ellipse, $\mathrm{cm}^{2}$ ) and COP mean Velocity (named VEL: the sum of the cumulated COP displacement divided by the total time, in $\mathrm{cm}^{2}$ ) in the anteroposterior (AP) and mediolateral (ML) directions of movement [40-42]. These parameters have been widely used to reflect postural stability, efficiency of the postural control systems and postural performance, respectively, in a variety of contexts [40-42].

\subsection{Data Analysis}

The main variables were described by means and standard deviation. The ShapiroWilk test was first used to evaluate the normality of the variables and determine which tests would be used. Student's $t$-test was used to compare the two group of pain (low vs. strong pain). For functional and postural control variables, the two groups were compared by independent Student $t$-test. To determine the magnitude of the differences between two pain groups, the percentage of clinical differences as well as the effect size were calculated according to Glass and Hopkins [43] using Hedge's coefficient $g$ [44] as: small $(g=0.20-0.49)$, moderate $(g=0.50-0.79)$ and large $(g \geq 0.80)$ based on our size sample. Finally, Pearson correlations between clinical measures and physical functional tests and postural control were performed as small $(0.1-0.30)$, moderate $(0.30-0.50)$ and strong $(>0.50)$ [45]. All statistical analyses were performed with a significant alpha risk of 
less than 0.05. IBM SPSS version 26.0 software (IBM, Armonk, NY, USA) was used for the statistical analysis.

\section{Results}

Sociodemographic (age, occupation, education level, household income, matrimonial status) and anthropometric (BMI and waist circumference) data are presented in Table 1. Overall, both groups (low and strong PI) were homogeneous.

Table 1. Sociodemographic and anthropometric outcomes.

\begin{tabular}{|c|c|c|c|}
\hline Outcomes & $\begin{array}{l}\text { Low-PI } \\
(n=14)\end{array}$ & $\begin{array}{l}\text { Strong-PI } \\
\quad(n=7)\end{array}$ & $p$-Value \\
\hline Age (years) & $56.6 \pm 4.7$ & $57.6 \pm 5.3$ & 0.66 \\
\hline $\mathrm{BMI}\left(\mathrm{kg} / \mathrm{m}^{2}\right)$ & $27.4 \pm 4.4$ & $34.4 \pm 9.4$ & 0.11 \\
\hline \multicolumn{4}{|l|}{ Occupation } \\
\hline Remunerated job & $8(57.1 \%)$ & $3(49.2 \%)$ & 0.44 \\
\hline Retired & $5(35.7 \%)$ & $2(28.6 \%)$ & \\
\hline Self-employed & $0(0.0 \%)$ & $1(14.3 \%)$ & \\
\hline Housewife & $1(7.1 \%)$ & $0(0.0 \%)$ & \\
\hline Disable & $0(0.0 \%)$ & $1(14.3 \%)$ & \\
\hline \multicolumn{4}{|l|}{ Education level } \\
\hline Secondary & $1(7.1 \%)$ & $2(28.6 \%)$ & 0.57 \\
\hline Professional & $4(28.6 \%)$ & $0(0.0)$ & \\
\hline College & $2(14.3 \%)$ & $1(14.3 \%)$ & \\
\hline Bachelor & $5(35.7 \%)$ & $3(42.9 \%)$ & \\
\hline Graduate and more & $2(14.3 \%)$ & $1(14.3 \%)$ & \\
\hline \multicolumn{4}{|l|}{ Household income (CAN\$) } \\
\hline$<15,000 \$$ & $0(0.0 \%)$ & $1(14.3 \%)$ & 0.06 \\
\hline 15,000 to $34,999 \$$ & $3(30.0 \%)$ & $0(0.0 \%)$ & \\
\hline 35,000 to $79,999 \$$ & $1(10.0 \%)$ & $4(57.1 \%)$ & \\
\hline$\geq 80,000 \$$ & $6(60.0 \%)$ & $2(28.6 \%)$ & \\
\hline \multicolumn{4}{|l|}{ Matrimonial status } \\
\hline Single & $1(7.1 \%)$ & $2(28.6 \%)$ & 0.70 \\
\hline Married & $8(57.1 \%)$ & $4(57.1 \%)$ & \\
\hline Common-law partner & $4(28.6 \%)$ & $1(14.3 \%)$ & \\
\hline Divorced & $1(7.1 \%)$ & $0(0.0 \%)$ & \\
\hline
\end{tabular}

Age, BMI and waist circumference are expressed as mean \pm SD (standard derivation). Other Data are expressed as $n(\%)$. PI = pain index; BMI = body mass index.

\subsection{Physical and Functional Capacity and Balance Performance}

The pain significantly $(p<0.05)$ affected three physical variables with Hedge's $g$ changes varying from -0.36 to 1.44 across clinical values of performance (Table 2$)$. Women in the strong PI group reported an increase in the time taken to perform the FTSST $(+60.57 \%$; $p \leq 0.08)$, a decrease in the number of repetitions of the Stair-Step Test $(-40.44 \% ; p \leq 0.001)$, a decrease in the distance during the Six-minute Walk Distance Test (6MWD: $-22.09 \%$; $p \leq 0.003)$ and an increase in the time to perform the TUG $(+24.33 \% ; p \leq 0.04)$ when compared to the low PI group.

Furthermore, significant differences between groups were reported for the amplitude of COP variable (AP) in anterior-posterior direction for the bipodal condition, during eyes open $(+20.29 \% ; p \leq 0.03)$ measures. These results on postural control were not confounded by BMI differences between groups $(p>0.05)$. BMI did not mediate any influence on postural control, suggesting that strong pain would mean poor postural control. 
Table 2. Differences between pain groups on anthropometric, physical capacity and postural control and coefficient correlations across these variables.

\begin{tabular}{|c|c|c|c|c|c|c|}
\hline Variable & $\begin{array}{c}\text { Low-PI } \\
n=14 \\
\text { Mean } \pm \text { SD }\end{array}$ & $\begin{array}{c}\text { Strong-PI } \\
n=7 \\
\text { Mean } \pm \text { SD }\end{array}$ & $\begin{array}{c}\text { Differences } \\
(\%)\end{array}$ & $\begin{array}{c}\text { Hedge's } \\
g\end{array}$ & $p$ Value & $\begin{array}{c}\text { Pearson's r } \\
(p \text { Value })\end{array}$ \\
\hline \multicolumn{7}{|l|}{ Anthropometric } \\
\hline BMI $\left(\mathrm{kg} / \mathrm{m}^{2}\right)$ & $27.78 \pm 7.36$ & $32.95 \pm 9.58$ & +18.61 & -0.57 & 0.11 & $0.36(0.13)$ \\
\hline Waist circumference $(\mathrm{cm})$ & $99.59 \pm 8.34$ & $104.34 \pm 16.43$ & +4.77 & -0.36 & 0.39 & $0.17(0.49)$ \\
\hline \multicolumn{7}{|l|}{ Physical and functional capacity } \\
\hline FTSST (seconds) & $9.73 \pm 2.38$ & $13.64 \pm 5.17$ & +40.18 & -0.97 & 0.08 & $0.53 *(0.02)$ \\
\hline Stair Step Test (repetitions) & $27.92 \pm 5.01$ & $19.88 \pm 5.26$ & -40.44 & 1.44 & $0.001 * *$ & $\begin{array}{c}-0.72 \text { ** } \\
(0.001)\end{array}$ \\
\hline 6MWD (meters) & $631.82 \pm 74.55$ & $517.50 \pm 78.61$ & -22.09 & 1.31 & $0.003^{* *}$ & $\begin{array}{c}-0.64^{* *} \\
(0.003)\end{array}$ \\
\hline \multirow[t]{2}{*}{ TUG (seconds) } & $5.63 \pm 0.95$ & $7.00 \pm 1.83$ & +24.33 & -0.93 & $0.04^{*}$ & $0.50 *(0.03)$ \\
\hline & $\begin{array}{c}\text { Low-PI } \\
n=12\end{array}$ & $\begin{array}{c}\text { Strong-PI } \\
n=7\end{array}$ & & & & \\
\hline \multicolumn{7}{|l|}{ Postural control (force platform) } \\
\hline VEL-COP Bipodal AP EO $(\mathrm{cm} / \mathrm{s})$ & $0.69 \pm 0.11$ & $0.83 \pm 0.17$ & +20.29 & -0.94 & 0.03 * & $0.49 *(0.03)$ \\
\hline VEL-COP Bipodal ML EO (cm/s) & $0.72 \pm 0.09$ & $0.78 \pm 0.18$ & +8.33 & -0.50 & 0.37 & $0.22(0.37)$ \\
\hline VEL-COP Bipodal AP EC $(\mathrm{cm} / \mathrm{s})$ & $0.85 \pm 0.15$ & $0.99 \pm 0.21$ & +16.47 & -0.73 & 0.11 & $0.38(0.11)$ \\
\hline VEL-COP Bipodal ML EC (cm/s) & $0.77 \pm 0.09$ & $0.80 \pm 0.16$ & +3.90 & -0.23 & 0.68 & $0.10(0.68)$ \\
\hline VEL-COP Semi-tandem AP EO $(\mathrm{cm} / \mathrm{s})$ & $1.00 \pm 0.17$ & $1.07 \pm 0.24$ & +7.00 & -0.32 & 0.46 & $0.18(0.46)$ \\
\hline VEL-COP Semi-tandem ML EO (cm/s) & $1.34 \pm 0.26$ & $1.43 \pm 0.32$ & +6.72 & -0.29 & 0.49 & $0.17(0.49)$ \\
\hline VEL-COP Semi-tandem AP EC ( $\mathrm{cm} / \mathrm{s})$ & $1.46 \pm 0.37$ & $1.58 \pm 0.38$ & +8.22 & -0.29 & 0.51 & $0.16(0.51)$ \\
\hline VEL-COP Semi-tandem ML EC $(\mathrm{cm} / \mathrm{s})$ & $2.08 \pm 0.60$ & $2.29 \pm 0.74$ & +10.10 & -0.29 & 0.51 & $0.16(0.51)$ \\
\hline
\end{tabular}

Data are expressed as mean \pm SD (standard derivation). PI = pain index; Low-PI = Low Pain Index group (PI $\leq 9)$ and Strong-PI = higher pain group $(\mathrm{PI} \geq 10) . \mathrm{BMI}=$ Body Mass Index; FTSST $=$ Five times sit to stand test; $6 \mathrm{MWD}=6$ min walk distance; $\mathrm{TUG}=$ Timed-up and Go; $\mathrm{AP}=$ anteroposterior; Postural control: VEL-COP (mean sway velocity of Centre of pressure: $\mathrm{COP}$ ) parameter. $\mathrm{AP}=$ anteroposterior; $\mathrm{ML}=$ mediolateral; $\mathrm{EO}=\mathrm{eyes}$ open $\mathrm{EC}=$ eyes close. ${ }^{*}$ Significant group differences $=p<0.05$, (Student $t$-test). ${ }^{* *}$ Significant group differences $=p<0.01$, (Student $t$-test). Pearson's coefficient correlations between pain measure and anthropometric, physical capacity and postural control variables. Significant correlations between these variables are illustrated for $* p<0.05$.

\subsection{Clinical and Functional and Balance Relationship}

As presented in Table 2, significant correlations were found between pain and FTSST $(\mathrm{r} \geq 0.53 ; p \leq 0.02)$; Stair-Step Test $(\mathrm{r} \geq-0.72 ; p \leq 0.001)$; $6 \mathrm{MWD}$ in meters $(\mathrm{r} \geq-0.64$; $p \leq 0.003)$; and TUG ( $\mathrm{r} \geq 0.50 ; p \leq 0.03)$. For the postural control tests, a significant correlation was found between pain and VEL-COP during the bipodal anteroposterior measure with eyes open $(\mathrm{r} \geq 0.49 ; p \leq 0.03)$. Overall, these correlations varied from weak to moderate across COP variables $(\mathrm{r}-0.01$ to -0.068$)$.

\section{Discussion}

The main finding of our study is that women who report higher hip pain have lower physical and functional capacity. Moreover, higher self-reported hip pain has a negative effect on functional postural control in women aged 45 to 64 years old. Overall, the functional impact of pain was rather negative for the women in this study. To our knowledge, few studies have focused exclusively on the same experimental design of the impact of hip pain on physical and functional capacity and postural control using COP parameters, including a total of 12 variables in the present study (Table 2).

The significant decrease in functionality related to pain is consistent with previous studies [11,46-49] and confirms that hip pain is extremely prevalent in an older communitybased population. However, some studies have reported a lower significant association between pain and some physical variables $[11,14,47]$. This difference could be attributed to the smaller sample size in our study or to variability in the choice of tests performed, mainly when comparing groups on postural control variables (only one significant difference was reported for COP values). Our study was also not based on diagnostic criteria for hip $\mathrm{OA}$, but on the subjective perception of hip pain. Overall, the present findings show an 
association between the intensity of hip pain and several factors that impact physical functions, such as functional variables associated with lower limb strength, speed and walking ability. Although discreet, significant correlations were also pointed out for postural control performance from COP values. High BMI was observed in both groups (mean 27.78 to 32.95), but without affecting postural control results between groups. As reported in Jeanmaire et al. [28], patients with low lean mass showed more pain. They report that in patients with knee and/or hip OA, normal BMI is associated with greater pain and impaired function than in those with higher BMI. Pan et al. [46] found that BMI may be associated with an increased risk of pain at several sites, both at weight-bearing sites such as the lower limbs and at non-weight-bearing sites such as the hands. This finding suggests that body weight has a substantial effect on the pathogenesis of pain. Indeed, it is recognized that adipose tissue serves as an endocrine organ producing cytokines and pro-inflammatory adipokines [50]. As reported by Hartvigsen et al. [51] and by Neogi [52], inflammation can lead to hypersensitivity to pain. It is possible that subjects with a higher BMI are more vulnerable to pain sensitivity. Perhaps the women in this study reported even, low pain experiences because of their body weight.

Moreover, the muscle strength decrease could be explained by the appearance of some form of kinesiophobia and motionlessness caused by pain [28]. Thus, pain could be responsible for a decrease in the amount of physical activity practiced, which could lead to a significant decrease in muscle mass and consequently, in muscle strength [11,28]. Indeed, literature is clear about the fact that muscle weakness and atrophy are characteristics that are present in subjects with osteoarthritis, regardless of the severity of their condition [53,54]. Our study shows a $40 \%$ increase in time to perform FTSST in participants in the higher hip pain group. This result is consistent with a previous study conducted by Jerez-Mayorga et al. [49] in which healthy subjects are compared with subjects with osteoarthritis. The performance of subjects with osteoarthritis was $34 \%$ slower in the Sit to Stand Test.

Some of the results of the present study corroborate the findings by Hall et al. [11] which show that greater strength in the hip and thigh muscles may be associated with better self-reported physical function. As reported by Mosler et al. [48] hip pain sufferers demonstrate impaired performance on functional tasks and postural control. Consistent with our study, Mosler, Kemp [48] also reported that hip-related pain demonstrates lower hip strength. The author recommends measuring strength using objective methods of measurement like dynamometry, preferring dynamometers with external fixation to minimize the potential systematic error of a handheld dynamometer, which was not done in our study.

Muscular strength and power are factors that enable motor and postural control. Decreasing these functions can lead to increased fall risk [55]. Falls are one of the main causes of morbidity and mortality in the adult population [6]. Some studies have shown that hip OA is associated with an increased fall risk [6,14,15,17,18]. De Zwart et al. [56] report that muscular strength is the most significant independent variable associated with fall risk in people with OA. Poor postural control, lower limb muscle weakness, decreased proprioception and pain may contribute to the increased incidence of falls in older adults $[14,18]$. In contrast to the results obtained in our study, a systematic review of Picorelli [14] reports that no significant difference could be observed in the time taken to perform the TUG. Our results showed that women reporting more pain had a $24 \%$ longer duration than women in the low pain group.

Another study conducted by Rydevik et al. [47] compared a functional control group with patients with hip OA. In contrast to our study, they reported no significant differences between the two groups in terms of muscle strength and aerobic capacity. However, as in our study, a significantly shorter distance was walked in the Six-Minute Walk Test.

The explanation for a lack of association between postural control and pain is not entirely clear. Differences when performing more difficult tasks such as the semi-tandem position may be less important. It is also possible that the range of postural control tests, 
equipment and duration of tests may have contributed to differences in findings in several studies. As opposed to the systematic review conducted by Picorelli et al. [14], our study has revealed that AP postural control was more impaired than ML postural control. The author showed some inconsistencies. The hip OA group showed greater ML sway with eyes open and greater AP sway with eyes closed compared to controls. Our study showed a significant increase in sway AP with eyes open in the strong PI group. Nevertheless, a trend towards decreased postural control was observed in the tasks performed in our study. This trend for deficits in postural control could be due to neuromuscular contributions.

To our knowledge, our study is the first to evaluate lower limb velocity in women under 65 years old and hip pain without arthroplasty. Our results showed that participants suffering from hip pain took $40 \%$ longer to complete the Stair-Step Test than those reporting less pain. These results could be explained by a decrease in muscle strength $[11,48]$.

In addition to the studies of Mosler, Kemp [48] and Damen, van Rijn [57], our study is one of few that presents data on hip pain in younger subjects. Hip OA is a condition that is particularly present in older patients. Early detection of symptoms is essential to implement actions that will allow to maintain optimal physical function and reduce fall risk with ageing.

Therefore, we suggest that future studies validate whether patients with hip pain or hip OA are aged between 45 and 64 years old. It is essential to determine early factors leading to severe hip OA to increase functional capacity, to delay or avoid hip replacement, to reduce fall risk, fractures and eventually morbidity and mortality. An earlier diagnosis would lead to timely interventions to ensure joint health for as long as possible.

\section{Limitation}

Limitations of our study include the use of a self-report questionnaire for pain assessment that did not include frequency and severity of pain. Additionally, the assessment of muscle strength was performed only with the Sit-to-Stand Test. As recommended by Mosler [48], more precise muscle strength measurements, such as those obtained with a dynamometer, would have provided more information on the strength of the lower limbs in several ranges of motion. Another limitation is the very small number of recruited participants. A very small sample size generates relatively low statistical power (possible type-2 errors mainly for postural control COP parameters). Therefore, further studies are required to determine whether hip pain, in this case secondary to hip OA, has a significant impact on anthropometric, physical and functional capacity and postural control in women aged 45-64 years old.

\section{Conclusions}

We observed hip pain, and some physical and functional limitations in our strong pain group. The main results of this study showed that hip pain had a significantly negative impact in the women evaluated on several physical and functional characteristics such as strength, endurance and speed of the lower limbs as well as, to a lower degree, on postural balance. These findings imply a decrease in quality of life in the medium and long term in these women. Further studies are needed to validate whether women 45-64 years old with hip pain could maintain their functional abilities before a diagnosis of OA.

Supplementary Materials: The following are available online at https:/ /www.mdpi.com/article/10.339 0/geriatrics7010010/s1, Table S1: Index of Severity for Osteoarthritis of the Hip by Lequesne et al.

Author Contributions: Conceptualization, T.C., R.A.d.S. and P.B.; methodology, P.B., T.C. and R.A.d.S.; validation, T.C. and R.A.d.S.; formal analysis, P.B. and R.A.d.S.; investigation, P.B.; resources, T.C. and R.A.d.S.; data curation, T.C.; writing—original draft preparation, P.B.; writing-review and editing, T.C., R.A.d.S. and P.B.; visualization, T.C. and R.A.d.S.; supervision, T.C. and R.A.d.S.; project administration, T.C. and R.A.d.S. All authors have read and agreed to the published version of the manuscript.

Funding: This work was supported by the PSDRc program from UQAC (granted in 2018). 
Institutional Review Board Statement: The study was conducted according to the guidelines of the Declaration of Helsinki, and approved by the Ethics Committee of University of Quebec at Chicoutimi (protocol code: 2019-181, 602.610.01 and date of approval: 20 July 2018).

Informed Consent Statement: Informed consent was obtained from all subjects involved in the study. Written informed consent has been obtained from the patient(s) to publish this paper.

Data Availability Statement: Not applicable.

Acknowledgments: We thank the patients and their families for their participation in this study. We thank our research assistants Mathieu Dallaire and Micheal Tremblay for your support during the postural control evaluation tests and Micheline Harvey for the English correction.

Conflicts of Interest: The authors declare no conflict of interest.

\section{References}

1. United Nations. World Population Ageing 2019; P.D. Department of Economic and Social Affairs, Ed.; United Nations: New York, NY, USA, 2020.

2. Salaffi, F.; Carotti, M.; Stancati, A.; Grassi, W. Health-related quality of life in older adults with symptomatic hip and knee osteoarthritis: A comparison with matched healthy controls. Aging Clin. Exp. Res. 2005, 17, 255-263. [CrossRef]

3. Moskowitz, R.W. Osteoarthritis: Diagnosis and Medical/Surgical Management; Lippincott Williams \& Wilkins: Philadelphia, PA, USA, 2007.

4. Pereira, D.; Peleteiro, B.; Araujo, J.; Branco, J.; Santos, R.; Ramos, E. The effect of osteoarthritis definition on prevalence and incidence estimates: A systematic review. Osteoarthr. Cartil. 2011, 19, 1270-1285. [CrossRef]

5. Murphy, L.B.; Helmick, C.G.; Schwartz, T.A.; Renner, J.B.; Tudor, G.; Koch, G.G.; Dragomir, A.D.; Kalsbeek, W.D.; Luta, G.; Jordan, J.M. One in four people may develop symptomatic hip osteoarthritis in his or her lifetime. Osteoarthr. Cartil. 2010, 18, 1372-1379. [CrossRef] [PubMed]

6. Van Schoor, N.; Lips, P.; Deeg, D. Clinical osteoarthritis of the knee and hip are associated with an increased fall risk. Innov. Aging 2017, 1 (Suppl. 1), 1050. [CrossRef]

7. Altman, R.D. Classification of disease: Osteoarthritis. In Seminars in Arthritis and Rheumatism; Elsevier: Miami, FL, USA, 1991.

8. Murphy, N.J.; Eyles, J.P.; Hunter, D.J. Hip osteoarthritis: Etiopathogenesis and implications for management. Adv. Ther. 2016, 33, 1921-1946. [CrossRef]

9. Rasch, A.; Byström, A.H.; Dalen, N.; Berg, H.E. Reduced muscle radiological density, cross-sectional area, and strength of major hip and knee muscles in 22 patients with hip osteoarthritis. Acta Orthop. 2007, 78, 505-510. [CrossRef]

10. Arokoski, M.H.; Arokoski, J.P.; Haara, M.; Kankaanpää, M.; Vesterinen, M.; Niemitukia, L.H.; Helminen, H.J. Hip muscle strength and muscle cross sectional area in men with and without hip osteoarthritis. J. Rheumatol. 2002, 29, 2185-2195.

11. Hall, M.; Wrigley, T.V.; Kasza, J.; Dobson, F.; Pua, Y.H.; Metcalf, B.R.; Bennell, K.L. Cross-sectional association between muscle strength and self-reported physical function in 195 hip osteoarthritis patients. In Seminars in Arthritis and Rheumatism; Elsevier: Merbourne, Australia, 2017.

12. Foucher, K.C.; Aydemir, B.; Huang, C.H.; Horras, M.; Chmell, S.J. Aerobic capacity and fatigability are associated with activity levels in women with hip osteoarthritis. J. Orthop. Res. 2021, 39, 1236-1244. [CrossRef]

13. Philbin, E.F.; Groff, G.D.; Ries, M.D.; Miller, T.E. Cardiovascular fitness and health in patients with end-stage osteoarthritis. Arthritis Rheum. Off. J. Am. Coll. Rheumatol. 1995, 38, 799-805. [CrossRef]

14. Picorelli, A.M.; Hatton, A.L.; Gane, E.M.; Smith, M.D. Balance performance in older adults with hip osteoarthritis: A systematic review. Gait Posture 2018, 65, 89-99. [CrossRef]

15. Smith, T.O.; Higson, E.; Pearson, M.; Mansfield, M. Is there an increased risk of falls and fractures in people with early diagnosed hip and knee osteoarthritis? Data from the Osteoarthritis Initiative. Int. J. Rheum. Dis. 2018, 21, 1193-1201. [CrossRef] [PubMed]

16. Arden, N.K.; Nevitt, M.C.; Lane, N.E.; Gore, L.R.; Hochberg, M.C.; Scott, J.C.; Pressman, A.R.; Cummings, S.R. Osteoarthritis and risk of falls, rates of bone loss, and osteoporotic fractures. Arthritis Rheum. Off. J. Am. Coll. Rheumatol. 1999, 42, 1378-1385. [CrossRef]

17. Prieto-Alhambra, D.; Nogues, X.; Javaid, M.K.; Wyman, A.; Arden, N.K.; Azagra, R.; Cooper, C.; Adachi, J.D.; Boonen, S.; Chapurlat, R.D. An increased rate of falling leads to a rise in fracture risk in postmenopausal women with self-reported osteoarthritis: A prospective multinational cohort study (GLOW). Ann. Rheum. Dis. 2013, 72, 911-917. [CrossRef]

18. Doré, A.L.; Golightly, Y.M.; Mercer, V.S.; Shi, X.A.; Renner, J.B.; Jordan, J.M.; Nelson, A.E. Lower-extremity osteoarthritis and the risk of falls in a community-based longitudinal study of adults with and without osteoarthritis. Arthritis Care Res. 2015, 67, 633-639. [CrossRef]

19. Knoop, J.; Van Der Leeden, M.; Van Der Esch, M.; Thorstensson, C.A.; Gerritsen, M.; Voorneman, R.E.; Lems, W.F.; Roorda, L.D.; Dekker, J.; Steultjens, M.P. Association of lower muscle strength with self-reported knee instability in osteoarthritis of the knee: Results from the Amsterdam Osteoarthritis Cohort. Arthritis Care Res. 2012, 64, 38-45. [CrossRef] 
20. Van der Esch, M.; Knoop, J.; van der Leeden, M.; Voorneman, R.; Gerritsen, M.; Reiding, D.; Romviel, S.; Knol, D.L.; Lems, W.F.; Dekker, J. Self-reported knee instability and activity limitations in patients with knee osteoarthritis: Results of the Amsterdam osteoarthritis cohort. Clin. Rheumatol. 2012, 31, 1505-1510. [CrossRef]

21. Arvin, M.; Hoozemans, M.J.; Burger, B.J.; Rispens, S.M.; Verschueren, S.M.; van Dieën, J.H.; Pijnappels, M. Effects of hip abductor muscle fatigue on gait control and hip position sense in healthy older adults. Gait Posture 2015, 42, 545-549. [CrossRef] [PubMed]

22. Johnson, V.L.; Hunter, D.J. The epidemiology of osteoarthritis. Best Pract. Res. Clin. Rheumatol. 2014, 28, 5-15. [CrossRef]

23. Palazzo, C.; Nguyen, C.; Lefevre-Colau, M.-M.; Rannou, F.; Poiraudeau, S. Risk factors and burden of osteoarthritis. Ann. Phys. Rehabil. Med. 2016, 59, 134-138. [CrossRef]

24. Busija, L.; Hollingsworth, B.; Buchbinder, R.; Osborne, R.H. Role of age, sex, and obesity in the higher prevalence of arthritis among lower socioeconomic groups: A population-based survey. Arthritis Care Res. 2007, 57, 553-561. [CrossRef]

25. Canizares, M.; Power, J.D.; Perruccio, A.V.; Badley, E.M. Association of regional racial/cultural context and socioeconomic status with arthritis in the population: A multilevel analysis. Arthritis Care Res. 2008, 59, 399-407. [CrossRef] [PubMed]

26. Mobasheri, A.; Batt, M. An update on the pathophysiology of osteoarthritis. Ann. Phys. Rehabil. Med. 2016, 59, 333-339. [CrossRef]

27. Jiang, L.; Rong, J.; Wang, Y.; Hu, F.; Bao, C.; Li, X.; Zhao, Y. The relationship between body mass index and hip osteoarthritis: A systematic review and meta-analysis. Jt. Bone Spine 2011, 78, 150-155. [CrossRef] [PubMed]

28. Jeanmaire, C.; Mazières, B.; Verrouil, E.; Bernard, L.; Guillemin, F.; Rat, A.-C. Body composition and clinical symptoms in patients with hip or knee osteoarthritis: Results from the KHOALA cohort. In Seminars in Arthritis and Rheumatism; Elsevier: Nancy, France, 2018.

29. National Heart, L.; Institute, B. Quality assessment tool for observational cohort and cross-sectional studies. Bethesda Natl. Inst. Health Dep. Health Hum. Serv. 2014. [CrossRef]

30. Lequesne, M.; Mery, C.; Samson, M.; Gerard, P. Indexes of severity for osteoarthritis of the hip and knee: Validation-value in comparison with other assessment tests. Scand. J. Rheumatol. 1987, 16 (Suppl. 65), 85-89. [CrossRef] [PubMed]

31. Whitney, S.L.; Wrisley, D.M.; Marchetti, G.F.; Gee, M.A.; Redfern, M.S.; Furman, J.M. Clinical measurement of sit-to-stand performance in people with balance disorders: Validity of data for the Five-Times-Sit-to-Stand Test. Phys. Ther. 2005, 85, 1034-1045. [CrossRef] [PubMed]

32. Kalinova, É.; Leone, M. Tests D'évaluation de la Capacité Fonctionnelle Chez L'adulte de 55 Ans et Mieux; PUQ: Montreal, QC, Canada, 2009.

33. Enright, P.L.; Sherill, D. ATS Statement: Guidelines for the six-minute walk test. Am. Thorac. Soc. AMJ Respir. Crit. Care Med. 2002, $166,111-117$.

34. Shumway-Cook, A.; Brauer, S.; Woollacott, M. Predicting the probability for falls in community-dwelling older adults using the Timed Up \& Go Test. Phys. Ther. 2000, 80, 896-903. [PubMed]

35. Da Silva, R.A.; Vieira, E.R.; Fernandes, K.B.; Andraus, R.A.; Oliveira, M.R.; Sturion, L.A.; Calderon, M.G. People with chronic low back pain have poorer balance than controls in challenging tasks. Disabil. Rehabil. 2018, 40, 1294-1300. [CrossRef]

36. Gutin, I. In BMI We Trust: Reframing the Body Mass Index as a Measure of Health. Soc. Theory Health 2018, 16, 256-271. [CrossRef] [PubMed]

37. Initiative, N.O.E. The Practical Guide: Identification, Evaluation, and Treatment of Overweight and Obesity in Adults; National Institutes of Health: New York, NY, USA, 2000.

38. Klein, S.; Allison, D.B.; Heymsfield, S.B.; Kelley, D.E.; Leibel, R.L.; Nonas, C.; Kahn, R. Waist circumference and cardiometabolic risk: A consensus statement from shaping America's health: Association for Weight Management and Obesity Prevention; NAASO, the Obesity Society; the American Society for Nutrition; and the American Diabetes Association. Am. J. Clin. Nutr. 2007, $85,1197-1202$

39. Oliveira, M.R.; Vieira, E.R.; Gil, A.W.; Teixeira, D.C.; Amorim, C.F.; da Silva, R.A. How many balance task trials are needed to accurately assess postural control measures in older women? J. Bodyw. Mov. Ther. 2019, 23, 594-597. [CrossRef] [PubMed]

40. Da Silva, R.A.; Bilodeau, M.; Parreira, R.B.; Teixeira, D.C.; Amorim, C.F. Age-related differences in time-limit performance and force platform-based balance measures during one-leg stance. J. Electromyogr. Kinesiol. 2013, 23, 634-639. [CrossRef] [PubMed]

41. Paillard, T. Plasticity of the postural function to sport and/or motor experience. Neurosci. Biobehav. Rev. 2017, 72, 129-152. [CrossRef] [PubMed]

42. Kadri, M.A.; Chevalier, G.; Mecheri, H.; Ngomo, S.; Lavallière, M.; da Silva, R.A.; Beaulieu, L.-D. Time course and variability of tendinous vibration-induced postural reactions in forward and backward directions. J. Electromyogr. Kinesiol. 2020, $51,102386$. [CrossRef] [PubMed]

43. Glass, G.; Hopkins, K. Statistical methods in education and psychology. Psyccritiques 1996, 41, 1224.

44. Hedges, L.V. Distribution theory for Glass's estimator of effect size and related estimators. J. Educ. Stat. 1981, 6, 107-128. [CrossRef]

45. Cohen, J. Statistical Power Analysis for the Behavioral Sciences, 2nd ed.; Hillsdale, N.J., Ed.; Lawrence Erlbaum: New York, NY, USA, $1988 ; 567 p$

46. Pan, F.; Laslett, L.; Blizzard, L.; Cicuttini, F.; Winzenberg, T.; Ding, C.; Jones, G. Associations between fat mass and multisite pain: A five-year longitudinal study. Arthritis Care Res. 2017, 69, 509-516. [CrossRef]

47. Rydevik, K.; Fernandes, L.; Nordsletten, L.; Risberg, M.A. Functioning and disability in patients with hip osteoarthritis with mild to moderate pain. J. Orthop. Sports Phys. Ther. 2010, 40, 616-624. [CrossRef] 
48. Mosler, A.B.; Kemp, J.; King, M.; Lawrenson, P.R.; Semciw, A.; Freke, M.; Jones, D.M.; Casartelli, N.C.; Wörner, T.; Ishøi, L. Standardised measurement of physical capacity in young and middle-aged active adults with hip-related pain: Recommendations from the first International Hip-related Pain Research Network (IHiPRN) meeting, Zurich, 2018. Br. J. Sports Med. 2020, 54, 702-710. [CrossRef]

49. Jerez-Mayorga, D.; Ríos, L.J.C.; Reyes, A.; Delgado-Floody, P.; Payer, R.M.; Requena, I.M.G. Muscle quality index and isometric strength in older adults with hip osteoarthritis. PeerJ 2019, 7, e7471. [CrossRef]

50. Ronti, T.; Lupattelli, G.; Mannarino, E. The endocrine function of adipose tissue: An update. Clin. Endocrinol. 2006, 64, 355-365. [CrossRef] [PubMed]

51. Hartvigsen, J.; Natvig, B.; Ferreira, M. Is it all about a pain in the back? Best Pract. Res. Clin. Rheumatol. 2013, 27, 613-623. [CrossRef] [PubMed]

52. Neogi, T. The epidemiology and impact of pain in osteoarthritis. Osteoarthr. Cartil. 2013, 21, 1145-1153. [CrossRef] [PubMed]

53. Loureiro, A.; Mills, P.M.; Barrett, R.S. Muscle weakness in hip osteoarthritis: A systematic review. Arthritis Care Res. 2013, 65, 340-352. [CrossRef]

54. Zacharias, A.; Pizzari, T.; English, D.; Kapakoulakis, T.; Green, R. Hip abductor muscle volume in hip osteoarthritis and matched controls. Osteoarthr. Cartil. 2016, 24, 1727-1735. [CrossRef]

55. Martinikorena, I.; Martínez-Ramírez, A.; Gómez, M.; Lecumberri, P.; Casas-Herrero, A.; Cadore, E.L.; Millor, N.; Zambom-Ferraresi, F.; Idoate, F.; Izquierdo, M. Gait variability related to muscle quality and muscle power output in frail nonagenarian older adults. J. Am. Med. Dir. Assoc. 2016, 17, 162-167. [CrossRef]

56. De Zwart, A.H.; van der Esch, M.; Pijnappels, M.A.; Hoozemans, M.J.; van der Leeden, M.; Roorda, L.D.; Dekker, J.; Lems, W.F.; van Dieën, J.H. Falls associated with muscle strength in patients with knee osteoarthritis and self-reported knee instability. J. Rheumatol. 2015, 42, 1218-1223. [CrossRef]

57. Damen, J.; van Rijn, R.M.; Emans, P.J.; Hilberdink, W.K.; Wesseling, J.; Oei, E.H.; Bierma-Zeinstra, S.M. Prevalence and development of hip and knee osteoarthritis according to American College of Rheumatology criteria in the CHECK cohort. Arthritis Res. Ther. 2019, 21, 4. [CrossRef] 